\title{
CONTRIBUIÇÕES PARA ALFABETIZAÇÃO CARTOGRÁFICA NOS ANOS INICIAIS DA EDUCAÇÃO BÁSICA
}

\author{
CONTRIBUTIONS TO \\ CARTOGRAPHIC LITERACY \\ IN THE EARLY YEARS OF \\ BASIC EDUCATION
}

\author{
Jacks Richard de Paulo* \\ Maria Antonia Tavares de Oliveira Endo** \\ Marta Bertin ${ }^{* * *}$
}

\section{RESUMO}

O curso de extensão "Contribuições para Alfabetização Cartográfica nos Anos Iniciais da Educação Básica" compreendeu atividades intra e extramurais à Universidade Federal de Ouro Preto (UFOP), com professores que atuam nesse nível de ensino, nas redes municipal e estadual de ensino das cidades de Ouro Preto e Mariana, MG, buscando promover a alfabetização cartográfica há um público desprovido de tais conhecimentos e que podem potencializar a leitura de mundo por meio das aulas de Geografia. O objetivo principal desta proposta de caráter extensionista foi proporcionar novas possibilidades metodológicas de ensino e de aprendizagem de Geografia para alfabetização cartográfica. Três encontros formativos ocorreram no Laboratório de Práticas Pedagógicas "Hebe Rola"/ICHS/UFOP, em 2016. O quarto e último encontro constituiu o trabalho de campo. Os dados demonstraram que as noções cartográficas podem e devem ser trabalhadas desde os Anos Iniciais da Educação Básica, pois possibilitam identificar e interpretar signos por parte dos alunos.

Palavras-chave: alfabetização cartográfica; anos iniciais; ensino e aprendizagem; geografia.

\section{ABSTRACT}

The extension course "Contributions to Cartographic Literacy in the early years of basic education" comprised activities that were carried out inside and outside the Federal University of Ouro Preto (UFOP), with teachers working at that level of education in the municipal and state school system of Ouro Preto and Mariana, two cities in the state of Minas Gerais. This project was developed seeking to promote cartographic literacy to a public that does not have this knowledge and that might improve their awareness of the world through Geography classes. The main objective of this proposal, which is part of a

\footnotetext{
* Professor da Universidade Federal de Ouro Preto (UFOP), MG - Brasil. E-mail: richard@ichs.ufop.br

** Professora da Universidade Federal de Ouro Preto (UFOP), MG - Brasil. E-mail: mariantonia@cead.ufop.br

*** Professora da Universidade Federal de Ouro Preto (UFOP), MG - Brasil. E-mail: marta.bertin@cead.ufop.br
} 
university extension project, was to provide teachers and students with new methodological possibilities to teach and learn Geography through cartographic literacy. Three training meetings were held at the Teaching Practice Laboratory "Hebe Rola"/ICHS/UFOP, in 2016. The fourth and last meeting consisted of field work. Data demonstrated that cartographic notions can and should be worked from the early years of basic education, since they make it possible for the students to identify and interpret signs.

Keywords: cartographic literacy; early years; teaching and learning; geography.

\section{Introdução}

Ao longo do processo de industrialização, a sociedade vem presenciando intensas transformações espaciais em decorrência das novas tecnologias, as quais têm ocasionado mudanças tanto no nível local quanto no nível global nos diversos setores da vida em sociedade. Neste contexto de transformaçóes e mudanças, surgem novas demandas para as crianças, jovens, adultos e idosos, que envolvem outros procedimentos necessários tanto para a representação, quanto para a leitura dos fatos e fenômenos geográficos.

Apesar da importância dos preceitos anteriores para a sociedade na contemporaneidade, podese inferir que grande parte da população, em diferentes faixas etárias, tem dificuldade de usufruir dos benefícios proporcionados por essa nova realidade no que se refere às representaçóes de mundo no desenvolvimento de suas relaçóes cotidianas.

$\mathrm{Na}$ literatura específica que trata sobre a temática em questão, há apontamentos de pesquisadores sobre a necessidade de melhor preparar as crianças desde os Anos Iniciais da Educação Básica, visto que isto pode contribuir para ampliar tanto a visão quanto a percepçáo de mundo, pois, paulatinamente, vão sendo apresentadas em diferentes momentos, a outras noçóes conceituais, as quais passam a ser vivenciadas nas relaçóes cotidianas dos indivíduos, ou seja, para além do universo específico das aulas de Geografia (CALLAI, 2005; OLIVEIRA, 2008).

Partimos da premissa de que, ao potencializar o processo de alfabetização cartográfica nesse nível de ensino, as crianças passam a ler algumas representaçóes e a estabelecer interpretaçóes, sobretudo, com visão crítica. Nessa linha de raciocínio, pensamos que as crianças podem ampliar o conhecimento tanto a respeito das contribuiçóes das informaçóes de mundo no seu dia a dia, quanto das repercussóes da não utilização destas por diferentes motivos, principalmente, por não se estar alfabetizado cartograficamente.

Diante do exposto, fundamentados nos pressupostos de que as noçóes cartográficas constituem elementos essenciais para que a criança saiba localizar e efetuar a leitura crítica dos aspectos geográficos, propusemos o projeto Alfabetização Cartográfica para os Anos Iniciais da Educação Básica, sob a perspectiva de uma formação continuada de professores que atuam no referido nível de ensino.

Tais proposiçóes emergem do fato de que é comum nos depararmos com pessoas que mencionam ter dificuldade tanto nas escolas de Educação Básica quanto nas Instituiçóes de Ensino Superior em relação à leitura das representaçóes cartográficas, em destaque, para orientação e localizaçáo (PAULO, 2013). Para Almeida e Nogueira (2009), tal problemática está eminentemente relacionada aos anos Iniciais da Educação Básica, pois, quando não se é alfabetizado cartograficamente, pode-se repercutir tal problemática nos níveis posteriores de ensino e com reflexos negativos nas relaçóes sociais.

Castrogiovanni e Costella (2006) também destacam a importância da alfabetização cartográfica para o desenvolvimento das relaçóes espaciais e sociais, por exemplo, a de possibilitar um planejamento de deslocamento espacial antes mesmo de sairmos de nossa residência, o que pode contribuir para escolhermos o melhor trajeto. Outro aspecto também evidente se refere à minimizaçáo de tempo para desempenhar diferentes tipos de atividades. 
Assim, buscou-se desenvolver metodologias que possam ser implementadas pelos professores para o ensino dos fatos geográficos, pois, como ressalta Paulo (2013), o dinamismo que ocorre em termos das constantes transformaçóes espaciais impulsiona novas formas e possibilidades tanto de representá-las quanto de interpretá-las. Portanto, fica evidente a pertinência e as possíveis contribuiçôes da alfabetização cartográfica para leitura de mundo.

As açóes desenvolvidas buscaram contribuir para que os docentes pudessem ver outras possibilidades de ensino e de aprendizagem que visam a formação de futuros leitores de representaçóes cartográficas, e que sejam capazes de codificar e decodificar os signos e significados, sobretudo, de forma crítica.

Os sujeitos sociais deste processo - os docentes - necessitam ter o domínio sobre o mundo das imagens que se apresenta em duas formas: imagens como representaçóes visuais e imagens de nossa mente.

Corroboram neste sentido Santaella e Nöth (2001, p. 15), ao enfatizarem que,

O primeiro domínio refere-se aos desenhos, pinturas, gravuras, fotografias e as imagens cinematográficas e televisivas. Imagens são consideradas como objetos materiais, signos que representam o nosso meio ambiente visual. O segundo é visto como imaterial, as imagens aparecem como visóes, fantasias, imaginaçóes, esquemas, modelos ou, em geral, como representaçóes mentais.

Destarte, o domínio sobre as formas das imagens pode contribuir para a codificação e decodificação dos signos e seus significados.

\section{Da alfabetizaçáo cartográfica a leitura de mundo}

Há muito tempo, a Cartografia vem sendo apontada pelos pesquisadores como uma das principais linguagens para o ensino de Geografia e para leitura das representaçóes de mundo, em todos os níveis de ensino.

A este respeito, Kozel (2007, p.123) retrata que "[...] a linguagem é um veículo de significados e valores sociais e o signo, ao refletir a realidade, manifesta a visão social da realidade, interpretada por alguém, pela sua vivência social”.

Segundo Paulo (2013), a mediação pedagógica realizada pelo professor para promover a alfabetizaçáo cartográfica de crianças precisa articular variados tipos de informaçóes de mundo de forma próxima à realidade delas e, ao mesmo tempo, em que seja capaz de provocar a criticidade frente às representaçóes.

Assim, conforme as premissas de Tardif (2002), seja na formação inicial e ou na formação continuada de professores, há necessidade de se ampliarem os saberes tácitos dos professores relativos à realidade que permeia o universo de sua respectiva sala de aula e a comunidade escolar, pois o fato de dominar apenas os conteúdos específicos não significa que se obterá sucesso no processo de ensino e aprendizagem de Geografia. Portanto, os professores precisam contemplar, no processo de mediação pedagógica, uma linguagem que esteja mais próxima do aluno e possibilite a construção do conhecimento de forma significativa.

A referência a uma representação do espaço, por mínima que seja, envolve articular os pensamentos sobre o que já conhecemos e sobre como podemos representar esse conhecimento. Nesse sentido, as representações do espaço envolvem conhecimento sobre 
proporçôes (escala), ou seja, a que tamanho devem ser reduzidas as informaçóes para então representá-las. Além da escala, os símbolos indicam a possibilidade de se comunicar algo que não está presente concretamente, mas que é representado, e que nos permite estabelecer diversas correlaçóes sobre a dinâmica espacial. Já a legenda se refere a um apoio para a leitura das informaçóes que estão na representaçấo, portanto, de uma forma geral, dá condiçóes para que a criança possa entender como se dão as formas de representação, de analisá-las e de utilização em suas relaçóes cotidianas.

De acordo com as proposiçóes de Vygotsky (1988), a zona de desenvolvimento proximal permite que a criança possa atingir outros níveis de desenvolvimento por meio da mediação do professor. Nesta linha de pensamento, o professor precisa propor aos seus alunos a elaboraçáo de suas próprias representaçóes e decodificá-las, para que, em tempo oportuno, possam se tornar efetivamente potenciais leitores das representaçóes cartográficas.

Pelas consideraçóes de Vygotsky (1988), pode-se inferir que, para a alfabetização cartográfica, a criança precisa ser motivada constantemente para a compreensão do mundo e suas formas de representaçáo por meio de símbolos, pois tais perspectivas podem contribuir para ampliar inicialmente a criação de símbolos, enquanto forma de representação das ideias e dos objetos, mediante sua capacidade de observação e de percepção dos fatos geográficos.

Pensar sobre um adulto que proceda de forma eficiente à orientação e localizaçáo pelo espaço também envolve pensar sobre a premência da mediação pedagógica desde os Anos Inicias da Educação Básica. Nesse sentido, as práticas de ensino de Geografia precisam ser (re)dimensionadas, tendo em vista a ampliaçáo do conhecimento sobre pontos de referências em relaçáo ao espaço terrestre. Por exemplo, a partir de seus pontos de referência conhecidos (espaço vivido), uma criança poderá oportunamente alcançar espaços mais longínquos (espaço percebido), ou seja, mais abstratos (ALMEIDA, 2006).

O processo de alfabetização cartográfica pode ser alvo de muitas dúvidas, dependendo da forma como é desenvolvido, e não ser significativo para as crianças. No entanto, de acordo com Ausubel (1980), os ensinamentos de Geografia na contemporaneidade procuram estimular as crianças a renovar as percepçóes do espaço, sobretudo, por meio da aprendizagem significativa, mediada pelas novas tecnologias. Considere-se, por exemplo, a observaçáo de seu percurso de casa até a escola, de trajetos dentro de seu bairro, que a partir de seu conhecimento prévio permite tanto a leitura quanto a compreensão desse espaço, por meio das representaçóes digitais.

$\mathrm{O}$ processo de alfabetizaçáo cartográfica precisa contemplar a busca pelo conhecimento de forma inter-relacionada com o cotidiano das crianças, visto que tais conhecimentos váo se desdobrar em suas relaçóes por toda a vida, ou seja, como um conhecimento pleno do espaço em que habita. Portanto, pode-se considerar que a alfabetização cartográfica está plenamente relacionada com as relaçóes cotidianas, de trabalho e econômicas que potencializam tanto o conhecer-se quanto o reconhecer-se no espaço e no lugar onde vive. 


\section{Percurso metodológico}

O curso de extensão denominado Contribuições para Alfabetização Cartográfica nos Anos Iniciais da Educaçáo Básica foi ofertado para 22 professores que atuam no referido nível de ensino na rede municipal e estadual das cidades de Ouro Preto e Mariana, MG.

O objetivo principal desta proposta de caráter extensionista foi proporcionar novas possibilidades metodológicas de ensino e de aprendizagem de Geografia para alfabetizaçáo cartográfica. Para tal, três encontros foram realizados nas dependências do Laboratório de Práticas Pedagógicas "Professora Hebe Rola" /ICHS/UFOP, sendo o quarto encontro no Circuito do Trem Ouro Preto/Mariana como atividade de campo, conforme descriçóes a seguir.

No primeiro encontro, houve um momento de sensibilizaçáo sobre a importância da alfabetizaçáo cartográfica para leitura de mundo. A seguir, foi proposto o desenvolvimento de uma atividade que envolvesse o percurso dos professores de suas residências até a escola onde trabalham.

Por ser um público tanto de escola rural quanto urbana, o nível de detalhe dos desenhos era diversificado. Apesar de serem adultos, muitas vezes, embora consiga formar um mapa mental, transportar isso para um desenho requer habilidades que muitos não dominam, principalmente, por não terem desenvolvido noçôes de pontos de visão.

No segundo encontro, procedeu-se à delimitação de um local que envolvesse as duas cidades e que pudessem ser desenvolvidas atividades que contemplassem a alfabetização cartográfica; para isso, selecionou-se o percurso do Circuito do Trem ${ }^{1}$ entre Ouro Preto e Mariana-MG.

Foi disponibilizado, em 22 computadores do laboratório de Práticas Pedagógicas/ ICHS/UFOP, o programa Google Earth. Assim, trabalhou-se o programa e as diferentes possibilidades de aplicação para delimitar, identificar e correlacionar os fatos geográficos em um local comum em suas relaçóes cotidianas dos professores e dos alunos.

No terceiro encontro, foi proposta a realização de uma oficina para construção de uma rosa dos ventos móvel. Para tanto, utilizaram-se materiais recicláveis, tais como: caixa de leite longa vida, papeláo, lápis de cor, régua e arame flexível. Os professores desenharam a rosa dos ventos, com a indicação dos pontos cardeais e colaterais e, após, embrulharam a caixa de leite longa vida e perfuraram ao centro. A seguir, passaram o arame flexível como manivela para girar a rosa dos ventos.

No quarto e último encontro, os professores formadores convidaram os professores cursistas para o trabalho de campo no Circuito do Trem. Durante o trajeto, os docentes puderam identificar os fatos geográficos previamente selecionados na imagem do Google Earth, além de efetuarem a identificação in loco das demais informaçôes disponibilizadas nas legendas das representaçóes construídas pelos mesmos, durante o segundo encontro.

\section{Discussão e análise de dados}

Os professores que participaram desse curso, sob a perspectiva de formação continuada, são, na sua maioria, do sexo feminino e acumulam bastante tempo de 
regência nos anos iniciais da Educaçáo Básica. A maior parte dos professores do grupo possui graduação em Pedagogia (Figuras 1, 2 e 3).

\section{Figura 1- Professores que Participaram do Curso}

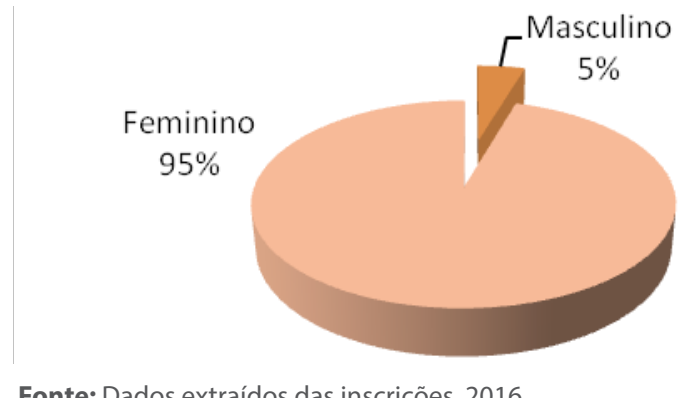

Fonte: Dados extraídos das inscrições, 2016.

\section{Figura 2- Professores/Tempo de Regência}

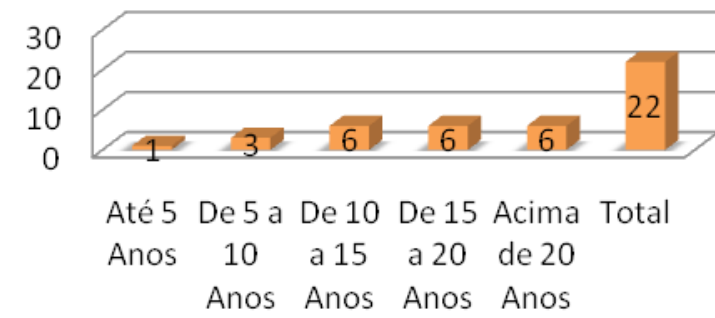

Fonte: Dados extraídos das inscrições, 2016.

\section{Figura 3- Professores por Curso de Formaçáo}

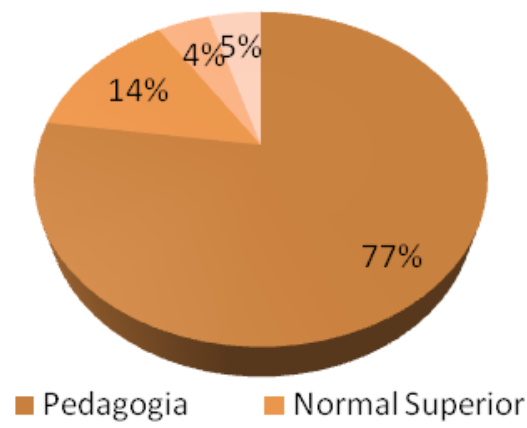

Fonte: Dados extraídos das inscrições, 2016.

No primeiro encontro, procedeu-se a uma reflexão sobre o mapa mental, ou seja, sobre as noçóes de espaço que cada indivíduo possui. De acordo com Bertin (2003), os mapas mentais são formados pelos elementos físicos pertencentes ao contexto sociocultural de cada pessoa, e se impóem como os mais característicos da paisagem rural ou urbana. Assim, o processo de conhecimento de um espaço é, em parte, influenciado pela experiência de cada um.

Foram trocadas várias informaçôes, um exemplo foi a colocação feita por um dos professores,

"Ao se levantar à noite com sede, não há necessidade de acender a luz, já se tem em mente o trajeto que deve ser seguido até o filtro" (Maria). 
Ao receberem uma folha de papel sulfite tamanho A4, os professores foram convidados a representar o percurso de sua casa até o Instituto de Ciências Humanas e Sociais da Universidade Federal de Ouro Preto. Em princípio, alguns reagiram e mencionavam ter dificuldades com desenhos, mas ao final todos realizaram a atividade.

Ao término, passamos para a análise e discussão dos desenhos, pois, na maioria dos casos, as representaçóes se iniciaram no meio da folha e não sobrou muito espaço para a finalização. Devido a tal aspecto, no início apareciam representaçóes de casas e ruas em maior proporção e depois bastante reduzidos em relaçáo ao tamanho das outras representaçôes (Figura 4).

\section{Figura 4- Percurso de Casa ao Instituto de Ciências Humanas e Sociais/UFOP}

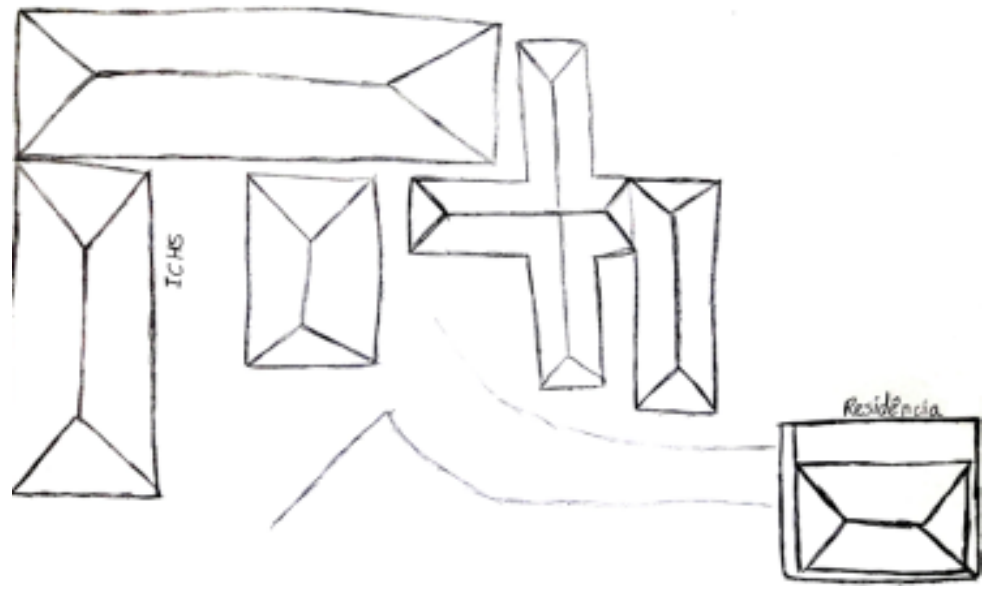

Fonte: Dado extraído de uma aluna de Mariana-MG, 2016.

Após as discussóes, os próprios professores apontaram a necessidade de planejar a representação com antecedência, envolvendo o tamanho do papel e a extensão do percurso a ser desenhado para evitar tal desproporção.

No segundo encontro com os professores, procedeu-se a uma reflexáo sobre o espaço, que conforme Callai (2005) deve ser entendido como um produto histórico, resultante das relaçôes sociais que vem se sucedendo ao longo de séculos, e como é possível compreender - por meio destas - as práticas sociais, o modo de vida dos habitantes e suas respectivas relações com o lugar.

De posse dessas informaçóes, foi proposta a construção do Circuito do Trem Ouro Preto e Mariana-MG, visando trabalhar conceitos basilares da área de Geografia, articulados com conhecimentos que permeiam o espaço de vivência das crianças (Figuras 5).

Para preparamos a criança para a leitura de mundo, há necessidade de se trabalhar a noção de espaço. De acordo Castrogiovanni e Costella (2006), tal noção se dá pela própria interação da criança com o meio em que vive e com as pessoas com quem vive. Portanto, tal noçáo compreende ideias e imagens que se reportam ao espaço de vivência, as quais são passíveis de serem representadas.

Na mesma linha de pensamento, Passini (1994) indica que o estudo do espaço somente tem significado se há consideraçáo das açóes cotidianas neste, para que possa perceber a complexa dinâmica que envolve a açáo humana de construir e reconstruir. 


\section{Figura 5- Circuito do Trem Ouro Preto/Mariana-MG}

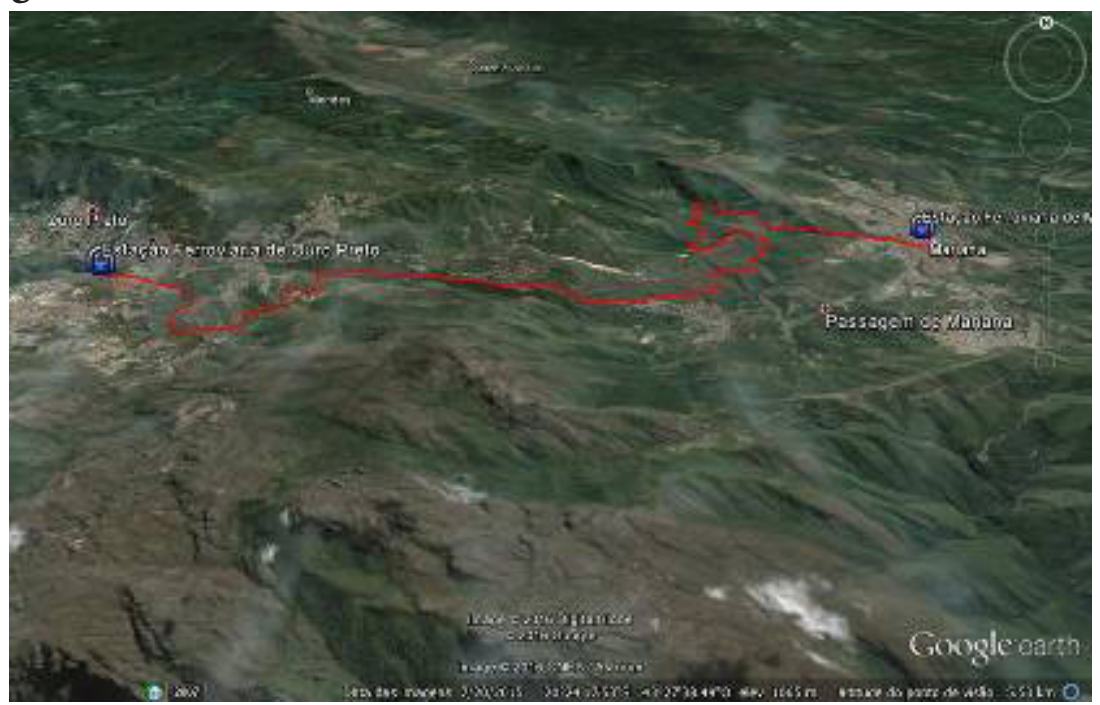

Fonte: Dados extraídos do Google Earth, 2016.

Desta forma, o percurso foi construído coletivamente, por meio da imagem baixada pelo programa Google Earth, possibilitando aos professores interagir sobre os procedimentos, para entáo criar as representaçóes sobre o circuito, ou seja, instrumentalizando-os através da representação cartográfica e da sua linguagem. Além destes, prosseguimos com as discussōes sobre as relaçôes topológicas, projetivas e euclidianas, que, como ressalta Almeida (2006), conduzem a criança à construçáo da noção de espaço vivido, percebido e concebido.

Portanto, para a construção de representação do circuito pelos professores, foram envolvidas características técnicas: tracejado da malha ferroviária, estaçáo nos dois municípios; conhecimento sobre a área física do percurso: hidrografia e formas de relevo, que forneceram subsídios para análise de uso e ocupação do solo. Assim, por meio de análise crítica, percebeu-se que a representação não revela na íntegra o que de fato se observa, mas pontua-se apenas o que foi atribuído como sendo de maior relevância. Portanto, a representação traz consigo a intencionalidade de quem a elaborou, ou seja, suas perspectivas, suas formas de observar, registrar e interpretar o mundo em um determinado contexto.

No terceiro encontro, foi elaborada uma rosa dos ventos móvel (Figura 6). Nesta atividade, foi possível analisar os elementos essenciais para se proceder a localizaçăo por meio da rosa dos ventos, com a indicação dos pontos cardeais e colaterais, além de aplicar os conhecimentos em interação com a bússola.

Todos os professores se deslocaram para o pátio do ICHS, onde se distribuíram para iniciar o exercício de localização. Assim, de acordo com a orientaçáo pelo Sol, indicavam a orientação de diferentes objetos. $\mathrm{Na}$ etapa seguinte, dando continuidade às atividades de orientaçáo, os alunos se deslocaram para outros lugares, para que os outros professores indicassem sua orientaçáo com o uso da rosa dos ventos. 
Figura 6- Rosa dos ventos móvel

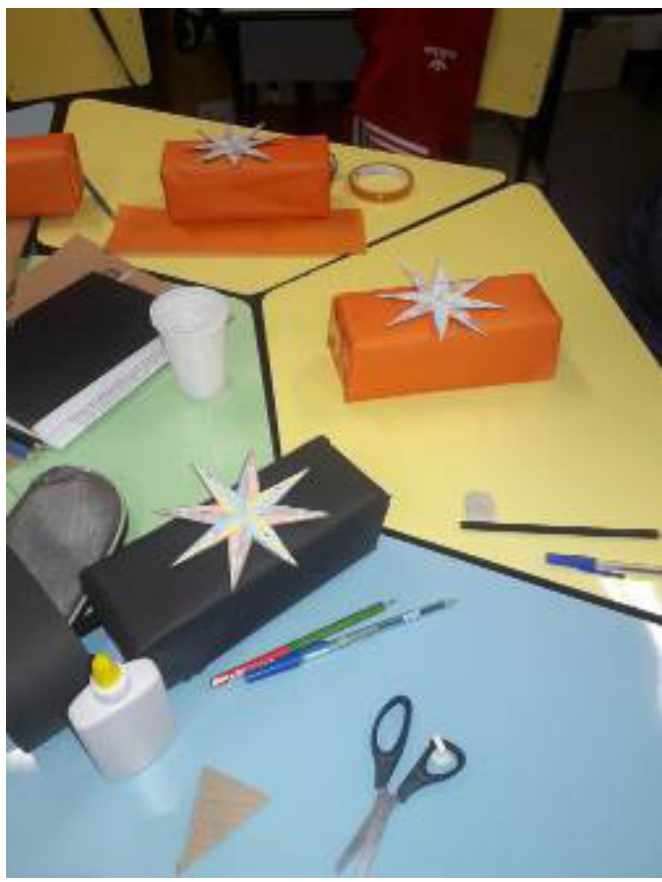

Fonte: Prática desenvolvida em oficina no Laboratório de Práticas Pedagógicas/ICHS/UFOP, 2016.

\section{Consideraçóes finais}

Conclui-se que a leitura de mundo náo pode se dar de forma dissociada em relação aos símbolos cartográficos, pois, para lermos as representações, há necessidade de apreendermos a codificação e a decodificação das mesmas, e, sobretudo, ser capaz de fazer a transposição para outras situações. Percebemos também que a noção de espaço é significativa quando se dá próxima à realidade, favorecendo oportunamente as relaçóes com espaços mais distantes.

Outro ponto observado é que o fato de alfabetizarmos cartograficamente nossos alunos faz com que estes passem a ser instrumentalizados para uma vida social, habilitados para interagir e compreender o seu espaço de vivência - o mundo.

Por fim, percebemos também que essa atividade de extensão possibilitou a vivência de momento singular em relação ao processo de formação continuada de professores, o de estar sempre em busca de outras possibilidades, de novos caminhos que possam (re) dimensionar outras práticas e que possam contribuir para a alfabetização cartográfica das crianças.

\section{Referências}

ALMEIDA, L. C.; NOGUEIRA, R. E. Iniciando a alfabetização cartográfica. Extensivo - Revista Eletrônica de Extensão, UFSC, v. 6, n. 7, 2009.

ALMEIDA, R. D. Do desenho ao mapa. São Paulo: Contexto, 2006. 115p. 
AUSUBEL, D. P.; NOVAK, J. D.; HANESIAN, H. Psicologia educacional. Rio de Janeiro: Interamericana, 1980.

BERTIN, M. 0 turismo em Foz do Iguaçu na visão dos estudantes: um estudo de percepção ambiental. 2003. 160 f. Dissertação (Mestrado em Geografia) - Setor de Ciências da Terra, Programa de Pós-Graduação em Geografia, Universidade Federal do Paraná, Curitiba, 2003.

CALLAI, H. C. A. Aprendendo a ler o mundo: a Geografia nos anos iniciais do ensino fundamental. Caderno Cedes, Campinas, v. 25, n. 66, p. 227-247, 2005.

CASTROGIOVANNI, A. C.; COSTELLA, R. Z. Brincar e cartografar com os diferentes mundos geográficos: a alfabetização espacial. Porto Alegre: Edipucrs, 2006.

KOZEL, S. Mapas mentais - uma forma de linguagem: perspectivas metodológicas. In: GIL FILHO, Sylvio F. et al. (Orgs.). Da percepção e cognição a representação: Reconstruções teóricas da geografia cultural e humanista. 1. ed. São Paulo: Terceira Margem, 2007.

OLIVEIRA, L. Estudo Metodológico e Cognitivo do Mapa. In: ALMEIDA, R. D. (Org.) Cartografia Escolar. São Paulo: Contexto, 2008.

PASSINI, E. Y. Alfabetização Cartográfica e o livro didático: uma análise crítica. Belo Horizonte: Editora Lê, 1994.

PAULO, J. R. Promovendo (re)significação de representações cartográficas no ensino de mapas: a constituição de uma parceria colaborativa com professores de geografia na educação básica. 2013. Tese (Doutorado em Educação) - Piracicaba, 2013.

SANTAELLA, L.; NÖTH, W. Imagem: Cognição, Semiótica, Mídia. São Paulo: Iluminuras, 2001.

TARDIF, Maurice. Saberes docentes e formação profissional. Petrópolis, RJ: Vozes, 2002.

VYGOTSKY, L. S. A formação social da mente. São Paulo: Martins Fontes, 1988. 